\title{
ARE TIMSS SCORES SUITABLE PROXIES FOR NATIONS' HUMAN CAPITAL?
}

\author{
Jiří Mazurek*
}

\begin{abstract}
:
To express human capital of nations proxies, such as literacy rates, school-enrollment rates or years of schooling are used. The aim of this article is to explore another possibility: to relate country's human capital to its outcome in TIMSS (The Third International Mathematics and Science Study), large international study of students' achievements in mathematics and science literacy from 1995. The relationship between TIMSS scores and GDP growth during 2000-2010 and GDP per capita in 2010 is examined and TIMSS are compared with other proxies of human capital, namely primary, secondary and tertiary school-enrollment rates from 1990, 1995 and 2000. The main result is that the correlation between TIMSS scores and GDP per capita in 2010 is statistically significant at $\alpha=0.01$ level, and this relationship is stronger than that for school-enrollment rates. Also, linear models explaining GDP growth with TIMSS were found more statistically significant than models without TIMSS. These results indicate that TIMSS scores might be considered a suitable proxy for nations' human capital after one or one and a half decade.
\end{abstract}

Keywords: economic growth, GDP per capita, human capital, TIMSS, TIMSS scores.

JEL Classification: C31, E01, I25

\section{Introduction}

Human capital is one of the most important intangible assets of enterprises as well as whole society. It is human knowledge, wit and ingenuity what drove our civilization to the use of satellites, lasers, cell phones, computers, Internet, nuclear power and many other technological conveniences. Introduction to the complexity of the concept of human capital can be found e. g. in Becker (1993) or Mazouch and Fischer (2011). According to Romer (1990), human capital is the key input for R\&D sector, which generates technological progress through new ideas and products. Countries with greater human capital are not only able to generate new knowledge, but they also introduce new goods more rapidly, which results into faster growth. As pointed by Nelson and Phelps (1966), human capital facilitates absorbing new ideas discovered elsewhere; hence countries with more human capital catch up with technological leaders and therefore grow faster.

Becker, Murphy and Tamura (1990) suppose that the rate of return on human capital grows as a consequence of the spillover benefits from human capital. If someone has some ability, for example talent in communication, this ability will be more appreciated

* Silesian University in Opava, School of Business Administration in Karviná, Univerzitní náměstí 1934/3, 73340 Karviná (mazurek@opf.slu.cz). 
by those who share it too. Increases in human capital per capita lead to higher investment into human capital and physical capital; and to higher per capita growth. Lucas (1988) in accordance with neo-classical approach to economic growth assumes that growth is driven by accumulation of human capital and the differences among countries' growth rates are primarily due to different accumulation rates of human capital.

Influence of human capital on economic growth has been studied widely in the recent decades; see e. g. Romer (1990), Barro (1991), Becker (1993), Baro and Sala-i-Martin (1995), Jones (1996), Temple (1999), Wilson and Briscoe (2004), Cohen and Soto (2007) or Castelló-Climent (2010). For the evaluation of nation's human capital, mostly the literacy rates, school-enrollment rates (both in \%) or duration of school attendance are used.

However, these measures of human capital have some disadvantages. Literacy rates in developed countries are almost identical: from 99 to $100 \%$. From the dataset of 21 countries considered in this paper only four (Cyprus, Italy, Slovenia and South Africa) had the literacy rates lower than 99\% in 1995 (UNESCO, 1998). That's why the literacy rates are not used as a proxy of human capital in this paper. The school-enrollment rates and duration of school attendance cannot embrace quality of education, as they are quantitative variables, but not qualitative.

In the 1990s the first large international comparative studies of students' and adults' knowledge were realized, including e.g. TIMSS (The Third International Mathematics and Science Study), PISA (Programme for International Student Assessment) or IALS (International Adult Literacy Study).

These studies enable another approach to the assessment of human capital among countries, which is based on their results. In this paper one large international education study, namely TIMSS conducted in 1995 across 40 countries all over the world, is used for the evaluation of nations' human capital. TIMSS 1995 results might be better proxies of nations' human capital on the following grounds:

- It describes real knowledge of students at a given level of education process in mathematics and science in a given country, regardless of government or private spending, school-enrollment rates, duration of school attendance in years and other parameters.

- Knowledge of mathematics and science is the most important driving force of nation's scientific and technology progress, which in turn can stimulate economic growth.

The question is whether TIMSS 1995 results are correlated with nations' economic growth and whether these correlations are more significant than for the aforementioned measures (proxies) of human capital. 
Therefore, the aim of the article is:

1) to examine the relationship between national TIMSS 1995 scores of 18-year old students, and economic growth and GDP per capita from 5 to 15 years later, when students reached their most productive years (thirties),

2) to compare the results of TIMSS with other proxies of human capital, namely school-enrollment rates.

The paper is organized as follows: in Section 2 earlier studies on the topic are briefly discussed, in Section 3 TIMSS research is described, in Section 4 the data and research methods are introduced, Section 5 provides results along with discussion and Conclusions close the article.

\section{The Relationship between Economic Growth and Human Capital}

From many studies on the role of human capital on economic growth only results of Barro's classic paper (Barro, 1991) will be discussed here. In this study the data of 98 countries all over the world from 1960 to 1985 were examined. Among others, the data included GDP per capita in 1960 (abbr. GDP60, in \$), the average growth rate of real per capita GDP from 1960 to 1985 (GR6085, in \%), primary school-enrollment rates from 1960 (PRIM60, in \%) and secondary school-enrollment rates from 1960 (SEC60, in \%).

As expected from the neoclassical growth models (see e.g. Solow 1956), due to diminishing returns to reproducible capital poor countries tend to grow faster than rich ones, and indeed, GR6085 depended negatively on GDP60.

Main Barro's finding dealing with human capital was that the average growth rate during 1960-1985 was positively related to proxies of initial human capital (from 1960), and this relationship was found statistically significant. When other variables were held constant, the regression coefficient between GR6085 and PRIM60 was 0.0250 and between GR6085 and SEC60 0.0305. For a human capital with the proxy defined as 0.0250 PRIM60 + 0.0305SEC60, the correlation coefficient with GR6085 was 0.73, this relationship is presented graphically in Figure 1.

Barro examined some other measures of human capital, such as school-enrollment rates from 1950 and 1970, and also literacy rates from 1960 (LIT60). The correlation coefficient between GR6085 and LIT60 was found significantly positive (as expected), when school-enrollment variables were excluded. However, with school-enrollment variables in the model the correlation coefficient of LIT60 was negative, a result difficult to interpret according to Barro. 
Figure 1

GDP per capita Growth (GR6085) vs. School-enrollment Variables

$(0.0250$ PRIM60 + 0.0305SEC60)

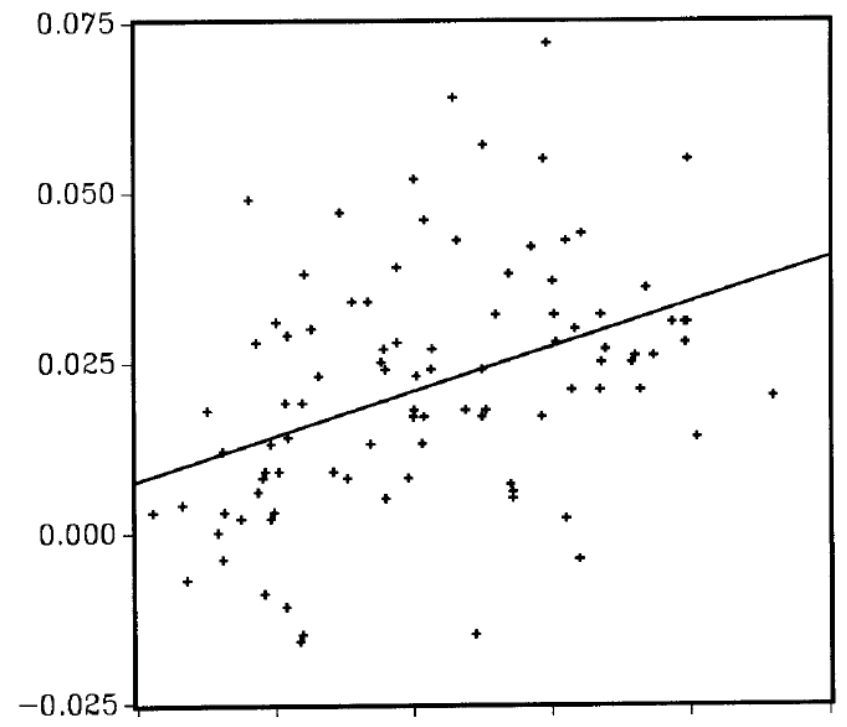

Source: Barro (1991).

\section{The Third International Mathematics and Science Study in $\mathbf{1 9 9 5}$}

The Third International Mathematics and Science Study (TIMSS) in 1995 was the first large international assessment of students' mathematics and science achievements conducted in more than 40 countries during 1994-1995 (for a list of all participating countries see TIMSS home page, 1995). Students of the third, fourth, seventh, and eighth grades, and the final year of secondary schools were tested in mathematics and science; altogether more than half a million students was tested.

In this paper only TIMSS 1995 scores of the final year of secondary school students (they are referred as Population 3) in mathematics and science literacy are discussed, as only these students were old enough in 1995 (they were eighteen years old) to have some impact on their national economies during 2000-2010 or 2005-2010 periods. Students of later TIMSS (or other) studies were too young to influence national economies in the given periods of time, so their results were not used in this paper. Altogether, the final year of secondary school students from 21 countries participated in TIMSS 1995, and their scores are shown in Table 1.

As for regional distribution of participating countries, it is very non-representative. There are sixteen countries from Europe, two countries of North America (USA and Canada), two countries of Australia and Oceania (Australia and New Zealand) and one country from Africa (South Africa). Asia, South and Central Americas are not represented at all. 
As can be seen from Table 1, the best results were achieved by Netherlands (559 points) and Scandinavian countries, while South Africa had the lowest scores (352 points). From non-European countries Canada, New Zealand and Australia had almost identical and slightly above average scores. Value 500 is the average across the means of all 21 countries.

The mathematics and science literacy test (for the test design and test items see TIMSS home page 1995 and TIMSS test items 1995, respectively) covered students' general mathematical and science knowledge and understanding of mathematical and science principles. In mathematical section (44 items) the test included fractions, percentages, proportionality, measurement, estimation and data analysis. In science section (32 items) real-world problems from life, earth and physical sciences were included. Here are examples of items from the test (TIMSS test items 1995):

Item A3. Experts say that $25 \%$ of all serious bicycle accidents involve head injuries and that, of all head injuries, $80 \%$ are fatal. What percentage of all serious bicycle accidents involves fatal head injuries?
a) $16 \%$
b) $20 \%$
c) $55 \%$
d) $105 \%$

Item D7. If there are 300 calories in 100 grams of a certain food, how many calories are there in a 30 gram portion of that food?
a) 90
b) 100
c) 900
d) 1000
e) 9000

Item D4. Electrical energy is used to power a lamp. Is the amount of light energy produced more, less than or the same as the amount of electrical energy used? Give a reason to support your answer.

\section{The Data and the Method}

\subsection{The data}

The data for each of 21 countries participating in TIMSS 1995 study and the Population 3 included:

- $\quad$ TIMSS scores from 1995, denoted as TIMSS95,

- GDP based on purchasing-power-parity (PPP) per capita in current international dollars from 1995, 2000, 2005 and 2010, denoted as GDP95, GDP00, GDP05 and GDP10,

- Mean annual GDP growth during 2005-2010 and 2000-2010 (in \%), denoted as GR05-10 and GR00-10 respectively,

- Primary school-enrollment rates from 1990, 1995 and 2000, denoted as PRIM90, PRIM95 and PRIM00,

- Secondary school-enrollment rates from 1990, 1995 and 2000, denoted as SEC90, SEC95 and SEC00,

- Tertiary school-enrollment rates from 1990, 1995 and 2000, denoted as TER90, TER95 and TER00, 
The above mentioned data are presented in Table 1 and Table 2. The data sources include:

- $\quad$ TIMSS: TIMSS 1995 Home Page (TIMSS home page 1995),

- GDP per capita, 1995, 2000, 2005 and 2010: International Monetary Fund, World Economic Outlook Database (International Monetary Fund 2011),

- $\quad$ School-enrollment rates: World Bank (World Bank 2010).

Table 1

TIMSS 1995 National Scores of the Final Year of Secondary School Students in Mathematics and Science Literacy along with Nations' GDP Data

\begin{tabular}{|l|c|c|c|c|c|c|c|}
\hline Country & TIMSS95 & GDP95 & GDP00 & GDP05 & GDP10 & GR05-10 & GR00-10 \\
\hline *Australia & 525 & 21.665 & 27.363 & 33.862 & 39.699 & 3.23 & 3.79 \\
\hline${ }^{*}$ Austria & 519 & 22.967 & 28.7 & 33.897 & 39.634 & 3.18 & 3.28 \\
\hline${ }^{*}$ Canada & 526 & 22.798 & 28.978 & 35.15 & 39.057 & 2.13 & 3.03 \\
\hline Cyprus & 447 & 16.668 & 20.394 & 24.816 & 28.255 & 2.63 & 3.31 \\
\hline Czech Rep. & 476 & 12.715 & 14.96 & 20.281 & 24.869 & 4.16 & 5.21 \\
\hline ***Denmark & 528 & 23.182 & 28.391 & 33.527 & 36.449 & 1.69 & 2.53 \\
\hline${ }^{*}$ France & 505 & 21.254 & 25.995 & 30.546 & 34.077 & 2.21 & 2.74 \\
\hline **Germany & 496 & 22.06 & 26.345 & 30.508 & 36.033 & 3.38 & 3.18 \\
\hline Hungary & 477 & 9.196 & 12.1 & 16.939 & 18.738 & 2.04 & 4.47 \\
\hline *Iceland & 541 & 20.648 & 26.943 & 35.272 & 36.620 & 0.75 & 3.12 \\
\hline${ }^{*}$ Italy & 475 & 20.571 & 24.54 & 27.944 & 29.392 & 1.02 & 1.82 \\
\hline Lithuania & 465 & - & 8.437 & 14.218 & 17.185 & 3.86 & 7.37 \\
\hline ***Netherlands & 559 & 23.157 & 29.731 & 35.02 & 40.764 & 3.08 & 3.21 \\
\hline New Zealand & 525 & 16.409 & 19.659 & 24.937 & 26.966 & 1.58 & 3.21 \\
\hline *Norway & 536 & 30.915 & 39.101 & 47.519 & 52.012 & 1.82 & 2.89 \\
\hline Russia & 476 & 6.418 & 7.657 & 11.881 & 15.836 & 5.92 & 7.54 \\
\hline ***Slovenia & 514 & 12.977 & 17.47 & 23.388 & 28.030 & 3.69 & 4.84 \\
\hline ***S. Africa & 352 & 5.778 & 6.639 & 8.653 & 10.497 & 3.94 & 4.69 \\
\hline Sweden & 555 & 20.632 & 26.533 & 33.146 & 38.031 & 2.79 & 3.67 \\
\hline Switzerland & 531 & 26.378 & 31.094 & 35.816 & 41.663 & 3.07 & 2.97 \\
\hline *USA & 471 & 27.826 & 35.251 & 42.68 & 47.283 & 2.07 & 2.98 \\
\hline
\end{tabular}

The legend: *Countries not satisfying guidelines for sample participation rates, ${ }^{* *}$ countries with unapproved student sampling, ${ }^{* * *}$ countries with unapproved sampling procedures and low participation rates. Sign '-' indicates missing data. Source: TIMSS home page (1995), IMF (2011).

Variables were divided into sets of independent variables: $I N D V=\{G D P 10, G R 00-05$, GR00-10 $\}$ and dependent variables: DEPV $=\{$ PRIM90, PRIM95, PRIM00, SEC90, SEC95, SEC00, TER90, TER95, TER00, GDP95\}. GDP95 was included into the set of dependent variables as well as into linear models, because GDP growth depends 
(negatively) on initial value of GDP (poorer countries tend to grow faster than rich ones), see also results of the empirical study by Barro (1991).

However, there were some minor problems with the data. School-enrollment rates in some countries and for some years were missing (see Table 2) as well as GDP from 1995 for Lithuania. Also, though TIMSS study was rather extensive, samplings in some countries did not satisfy strict guidelines for sampling of students, see Table 2 again. Nevertheless, TIMSS still provided the best data on students' achievements in the 1990s worldwide. School-enrollment rates are given as a gross enrollment ratio, which is the ratio of total enrollment, regardless of age, to the population of the age group that officially corresponds to the level of education shown (World Bank 2010). Hence, in some cases school-enrollment rates might exceed $100 \%$, as older students could participate in education of younger students.

Table 2

Primary, Secondary and Tertiary School-enrollment Rates (in \%) from 1990, 1995 and 2000 for Countries Participating in TIMSS 1995 Study

\begin{tabular}{|l|c|c|c|c|c|c|c|c|c|}
\hline Country & PRIM90 & PRIM95 & PRIM00 & SEC90 & SEC95 & SEC00 & TER90 & TER95 & TER00 \\
\hline Australia & 106.02 & 101.13 & 100.80 & - & 143.07 & 161.78 & 35.11 & 70.37 & 65.48 \\
\hline Austria & 101.10 & 102.84 & 102.93 & 100.61 & 105.12 & 98.07 & 32.65 & 45.37 & 55.67 \\
\hline Canada & 103.63 & 101.70 & 99.48 & 99.92 & 104.99 & 102.90 & 89.27 & 90.22 & 59.33 \\
\hline Cyprus & 89.07 & 99.88 & 96.73 & 70.72 & 94.85 & 87.98 & 11.23 & 17.02 & 19.56 \\
\hline Czech Rep. & 95.82 & 102.73 & 103.27 & 92.70 & 95.70 & 87.98 & 15.82 & 20.75 & 29.42 \\
\hline Denmark & 98.22 & 99.86 & 101.12 & 109.05 & 118.41 & 126.78 & 34.08 & 45.46 & 57.56 \\
\hline France & 109.55 & 105.83 & 105.35 & 96.27 & 112.63 & 108.80 & 36.75 & 50.58 & 53.30 \\
\hline Germany & - & 100.32 & 105.54 & - & 104.63 & 98.59 & - & 44.26 & - \\
\hline Hungary & 90.42 & 99.97 & 101.90 & 86.99 & 91.34 & 95.10 & 14.63 & 21.74 & 37.29 \\
\hline Iceland & 101.48 & 98.31 & 101.17 & 97.89 & 102.67 & 108.07 & 25.48 & 35.52 & 45.46 \\
\hline Italy & 98.38 & 99.56 & 103.11 & 78.83 & 88.06 & 93.28 & 29.37 & 40.84 & 48.63 \\
\hline Lithuania & 88.81 & 98.14 & 104.49 & 95.36 & 84.34 & 97.64 & - & 26.47 & 50.38 \\
\hline Netherlands & 102.46 & 107.18 & 108.04 & 118.62 & 139.15 & 122.69 & 35.65 & 47.53 & 52.09 \\
\hline New Zealand & 105.77 & 101.13 & 98.86 & 101.30 & 115.74 & 116.13 & 39.26 & 58.49 & 65.98 \\
\hline Norway & 99.61 & 98.48 & 100.61 & 89.93 & 113.16 & 110.38 & 38.51 & 54.35 & 69.21 \\
\hline Russia & 106.77 & 106.64 & 106.14 & 94.77 & - & - & 53.55 & 42.70 & - \\
\hline Slovenia & 100.73 & 98.02 & 97.93 & 88.25 & 91.47 & 100.44 & 24.33 & 30.99 & 55.57 \\
\hline S. Africa & 106.86 & 117.65 & 106.08 & 65.98 & - & 85.50 & 11.95 & - & - \\
\hline Sweden & 99.51 & 103.75 & 109.16 & 90.27 & 130.91 & 151.99 & 30.66 & 42.50 & 67.19 \\
\hline Switzerland & 88.88 & 95.80 & 105.54 & 97.57 & 101.00 & 95.00 & 25.69 & 31.62 & 37.68 \\
\hline USA & 104.97 & 102.61 & 99.87 & 92.19 & 95.82 & 92.91 & 71.71 & 77.35 & 67.50 \\
\hline
\end{tabular}

Note: Sign '-' indicates missing data.

Source: World Bank (2010). 


\subsection{The method}

To answer the question from the article's title positively, TIMSS scores should provide the same or higher explanation power of GDP level or/and GDP growth than other proxies of human capital. Hence, the examination whether TIMSS scores can be used as a suitable proxy of human capital (based on the sample of countries participating in TIMSS 1995 study) a comparison with other proxies, namely primary, secondary and tertiary school-enrollment rates from 1995 (1990, 2000) was carried out in two stages:

i) Simple linear regressions with TIMSS95 as an independent variable were compared to simple linear regressions with school-enrollment rates as independent variables for selected dependent variables from $D E P V$. For results see Section 5.2. Moreover, correlations among all variables are presented in Table 4.

ii) Multiple linear regressions with a selected dependent variable from $D E P V$ and selected independent variables from INDV. Again, models with TIMSS95 among explanatory variables were compared to models without TIMSS95. For the results and their discussion see Section 5.3.

A multiple linear regression model with $k$ independent variables is given as:

$$
y_{i}=\beta_{0}+\beta_{1} x_{1 i}+\beta_{2} x_{2 i}+\ldots+\beta_{k} x_{k i}+\varepsilon_{i}
$$

In (1) $y$ is dependent (explained) variable, $x_{j i}$ is the $i^{\text {th }}$ observation of $j^{\text {th }}$ independent (explanatory) variable, $\beta_{j}$ are regression coefficients and $\varepsilon_{i}$ are residuals. Goodness-offit of a model is given by $R^{2}$, the statistical significance of a model can be tested by the Fisher-Snedecor test (F-test), while the statistical significance of each particular $\beta_{i}$ can be checked by the Student test (t-test).

The estimation (1) was performed by OLS method via statistical software Gretl. When heteroscedasticity is present in the data, OLS does not result in biased estimation of parameters, but the method does not provide estimation with the lowest variance (estimation is inefficient), hence it leads to bias in test of statistical significance and confidence intervals. To avoid the problem with heteroscedasticity in the data, estimations (1) were corrected for heteroscedasticity.

Another problem in multiple regression models is multicollinearity, which might result into large changes in estimated regression coefficients and lower statistical significance of individual predictors. Multicollinearity of regression models was examined in the Section 5.3. 


\section{Results}

\subsection{Correlations among all variables}

Correlation coefficients among all variables are presented in Table 4. Statistically significant relationships between $I N D V$ and $D E P V$ variables were found only for GDP10 with TIMSS95, TER95 and TER00, respectively. Somewhat surprisingly, both GRO0-10 and GR05-10 were negatively correlated with TIMSS and TER variables, and mostly positively correlated with $P R I M$ variables. However, these relationships were not statistically significant. Among all variables, the strongest linear dependence was between GDP95 and GDP10, TER95 and TER00, and SEC90 and SEC95. PRIM variables were correlated substantially lower. TIMSS95 was correlated mostly with SEC90 and SEC95.

One possible explanation for the negative correlations between GR00-10 (GR05-10) and TIMSS95 (TER variables) is that from the neoclassical model of economic growth it follows that rich countries (with generally well-educated population) tend to grow slower than poorer countries (with generally less educated population), though all countries in the sample experienced growth during examined period. Also, the data might be disturbed by the financial crisis, which began in 2007. In the next two Sections selected simple and multiple linear models are examined.

\subsection{Simple linear regressions}

In this Section simple linear regression models were examined. All results are presented in Table 3. Also, to illustrate the relationship between TIMSS scores and GDP, Figures 2 and 3 are provided at the end of this section. Apparent 'outliers' on both figures are TIMSS scores of South Africa. However, it is not a case of a measurement error, as these scores are real results achieved by South African students, so the data for South Africa were used in the models hereinafter.

Models (1-3) include TIMSS95 as explanatory variable, while models (4-12) contain school-enrollment rates from 1995 as explanatory variables. Dependent variables were GDP10, GR05-10 and GR00-10. While models (1-3) provide explanation of GDP by (solely) TIMSS95, models (4-12) provide explanation of GDP by one of school-enrollment rates. In such a way both proxies of human capital (TIMSS and school-enrollment rates) can be directly compared in terms of good-of-fitess of presented models.

Comparison of the statistical significance of explanatory variables in these models suggests that TIMSS95 are suitable proxies of human capital, as they are highly significant in models (1) and (3). Among school-enrollment proxies SEC95 is statistically significant only in the model (7), PRIM95 only in the model (6) and TER95 is significant in all three models (10-12), but with only in the model (10). 
Table 3

Simple Linear Regression Models

\begin{tabular}{|c|c|c|c|c|c|c|c|}
\hline $\begin{array}{c}\text { Model } \\
\text { No. }\end{array}$ & $N, F, R^{2}$ & $\begin{array}{l}\text { dep. } \\
\text { var. }\end{array}$ & $\begin{array}{c}\text { indep. } \\
\text { var. }\end{array}$ & coef. & error & $p$-value & signif. \\
\hline \multirow{2}{*}{ (1) } & \multirow{2}{*}{$\begin{aligned} N & =21 \\
F(\text { sign. }) & =7.08 e-07 \\
\left.R^{2} \text { (adj. }\right) & =0.720\end{aligned}$} & \multirow{2}{*}{ GDP10 } & const & -42.8954 & 10.6144 & 0.0007 & $* * *$ \\
\hline & & & TIMSS95 & 0.151214 & 0.020874 & $<0.00001$ & $* * *$ \\
\hline \multirow{2}{*}{ (2) } & \multirow{2}{*}{$\begin{array}{c}\mathrm{N}=21 \\
\mathrm{~F}(\text { sign. })=0.158 \\
\left.\mathrm{R}^{2} \text { (adj. }\right)=0.054\end{array}$} & \multirow{2}{*}{ GR00-10 } & const & 6.81425 & 2.36213 & 0.00949 & $\star * *$ \\
\hline & & & TIMSS95 & 0.00641343 & 0.0043677 & 0.15837 & \\
\hline \multirow{2}{*}{ (3) } & \multirow{2}{*}{$\begin{array}{c}N=21 \\
F(\text { sign. })=0.0002 \\
\mathrm{R}^{2} \text { (adj.) }=0.720\end{array}$} & \multirow{2}{*}{ GR05-10 } & const & 6.66779 & 0.692478 & $<0.00001$ & $* * *$ \\
\hline & & & TIMSS95 & 0.00776093 & 0.0016905 & 0.00020 & $* * *$ \\
\hline \multirow{2}{*}{ (4) } & \multirow{2}{*}{$\begin{array}{c}\mathrm{N}=21 \\
\mathrm{~F}(\text { sign. })=0.127 \\
\left.\mathrm{R}^{2} \text { (adj. }\right)=0.072\end{array}$} & \multirow{2}{*}{ GDP10 } & const & 121.925 & 55.5659 & 0.04085 & ** \\
\hline & & & PRIM95 & -0.882664 & 0.552393 & 0.12656 & \\
\hline \multirow{2}{*}{ (5) } & \multirow{2}{*}{$\begin{array}{c}\mathrm{N}=21 \\
\mathrm{~F}(\text { sign. })=0.025 \\
\left.\mathrm{R}^{2} \text { (adj. }\right)=0.199\end{array}$} & \multirow{2}{*}{ GR00-10 } & const & -1.69509 & 2.55123 & 0.51440 & \\
\hline & & & PRIM95 & 0.0542749 & 0.0222392 & 0.02463 & ** \\
\hline \multirow{2}{*}{ (6) } & \multirow{2}{*}{$\begin{aligned} N & =21 \\
F(\text { sign. }) & =0.042 \\
\left.R^{2} \text { (adj. }\right) & =0.159\end{aligned}$} & \multirow{2}{*}{ GR05-10 } & const & -7.21751 & 4.67546 & 0.13915 & \\
\hline & & & PRIM95 & 0.0981777 & 0.0449193 & 0.04157 & ** \\
\hline \multirow{2}{*}{ (7) } & \multirow{2}{*}{$\begin{array}{c}N=19 \\
F(\text { sign. })=0.0016 \\
\left.R^{2} \text { (adj. }\right)=0.420\end{array}$} & \multirow{2}{*}{ GDP10 } & const & -5.24091 & 9.50904 & 0.58870 & \\
\hline & & & SEC95 & 0.346588 & 0.0924699 & 0.00160 & $* * *$ \\
\hline \multirow{2}{*}{ (8) } & \multirow{2}{*}{$\begin{array}{c}N=19 \\
F(\text { sign. })=0.596 \\
\left.R^{2} \text { (adj. }\right)=-0.041\end{array}$} & \multirow{2}{*}{ GR00-10 } & const & 3.87845 & 1.33704 & 0.00995 & $* * *$ \\
\hline & & & SEC95 & -0.00640439 & 0.0118418 & 0.59564 & \\
\hline \multirow{2}{*}{ (9) } & \multirow{2}{*}{$\begin{array}{c}N=19 \\
F(\text { sign. })=0.715 \\
R^{2}(\text { adj. })=-0.050\end{array}$} & \multirow{2}{*}{ GR05-10 } & const & 1.96705 & 1.44094 & 0.19001 & \\
\hline & & & SEC95 & 0.00473748 & 0.0127735 & 0.71531 & \\
\hline \multirow{2}{*}{ (10) } & \multirow{2}{*}{$\begin{array}{c}N=20 \\
F(\text { sign. })=0.0082 \\
\left.R^{2} \text { (adj. }\right)=0.291\end{array}$} & \multirow{2}{*}{ GDP10 } & const & 20.5221 & 4.61443 & 0.00031 & *** \\
\hline & & & TER95 & 0.287714 & 0.0969525 & 0.00825 & $* * *$ \\
\hline \multirow{2}{*}{ (11) } & \multirow{2}{*}{$\begin{array}{c}\mathrm{N}=20 \\
\mathrm{~F}(\text { sign. })=0.093 \\
\left.\mathrm{R}^{2} \text { (adj. }\right)=0.101\end{array}$} & \multirow{2}{*}{ GR00-10 } & const & 4.60265 & 0.690459 & $<0.00001$ & $* * *$ \\
\hline & & & TER95 & -0.018944 & 0.0106792 & 0.09299 & * \\
\hline (12) & $\begin{array}{c}N=20 \\
F(\text { sian })=0.065\end{array}$ & GR05-10 & const & 3.30165 & 0.518456 & $<0.00001$ & *** \\
\hline & $R^{2}(\operatorname{adj})=0.131$. & & TER95 & -0.013018 & 0.00661891 & 0.06481 & * \\
\hline
\end{tabular}




\section{Figure 2}

The Relationship between National TIMSS Scores in 1995 and Mean GDP Growth per capita (in \%) during 2005-2010 with Linear Trend

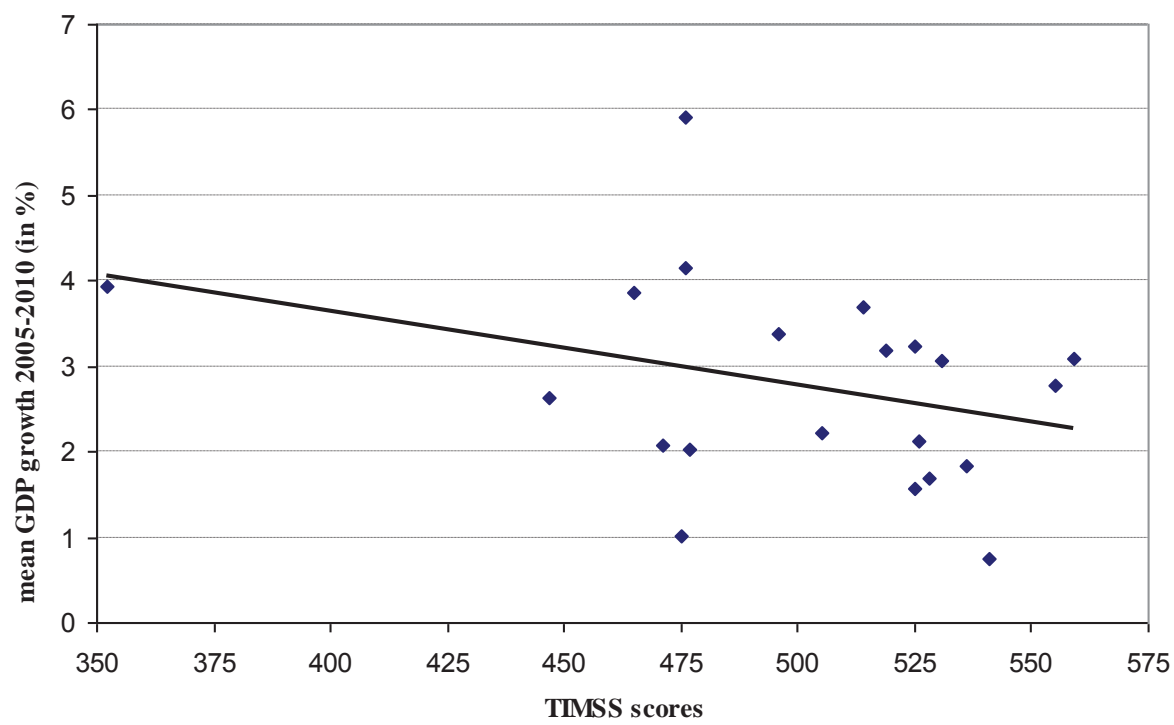

Figure 3

The Relationship between National TIMSS Scores in 1995 with GDP per capita (in $10^{3} \$$ ) in 2010 with Linear Trend

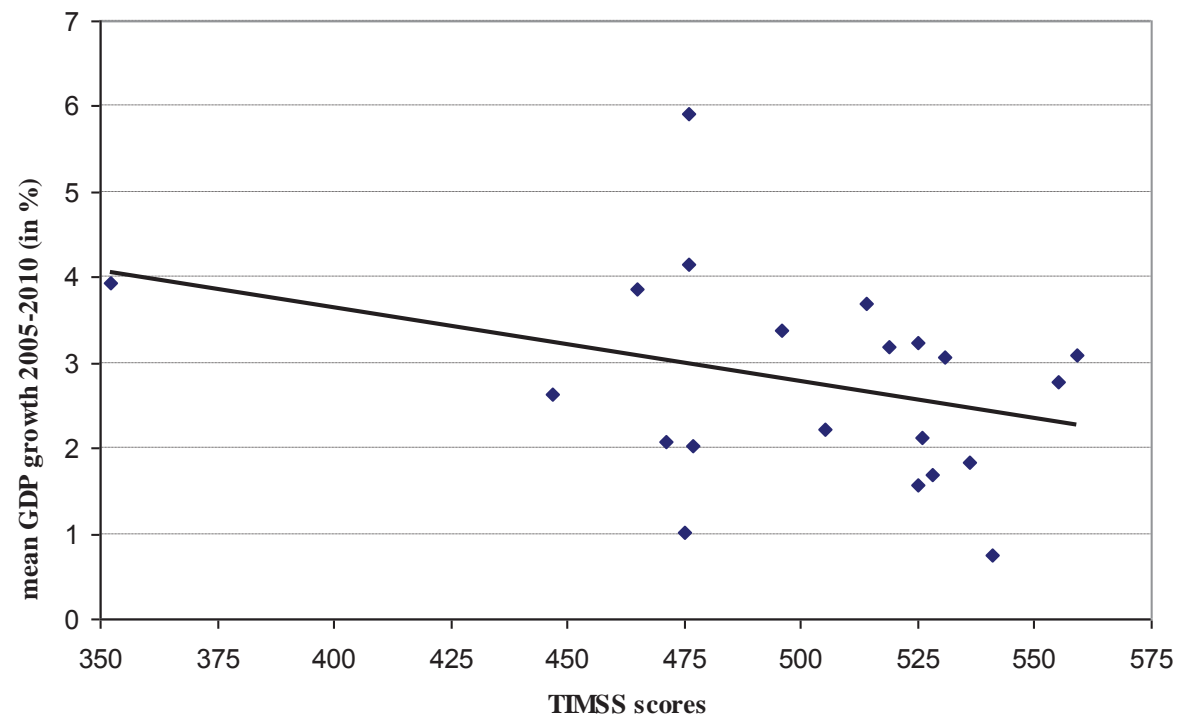




\subsection{Multiple linear regressions}

In this section multiple linear regression models with GDP10, GR05-10 or GR00-10 as dependent variables and school-enrollment rates along with TIMSS95 and GDP95 as independent (explanatory) variables were examined. More specifically, models with TIMSS95 as one of explanatory variables are compared with their counterparts without TIMSS95. If addition of TIMSS95 variable into the models results in a better model, then it can be considered a suitable proxy of human capital.

Models are numbered from (1) to (10) and are shown in Table 5 along with samples' sizes, regression coefficients, their overall statistical significance tested by $F$-test along with statistical significance of partial regression coefficients for each independent variable.

GDP95 was added among independent variables because in the neoclassical approach to the economic growth GDP growth is related (negatively) to the initial level of GDP per capita, as discussed in Sections 1 and 2. And indeed, as can be seen from Table 5 and columns (4) to (12), there is a negative and in most cases also statistically significant dependence between GDP95 and GR00-10 (or GR05-10).

In models (1-2) GDP10 was used as a dependent variable and PRIM95, SEC95, TER95 and TIMSS95 as explanatory variables. $F$-significance and $R^{2}$ values indicate that the better model was (1) with TIMSS95. Also, in the model (1) TIMSS95 was the most statistically significant variable.

In models (3-4) GR00-10 was used as a dependent variable and GDP95, PRIM95, SEC95, TER95 and TIMSS95 as explanatory variables. In the model (3) with TIMSS95 only TER 95 was found to be statistically significant (at 0.10 level), though $F$-significance of the model was very small (0.00087). In the model (4) GDP10 was the only significant explanatory variable. Values of $F$-significance and $R^{2}$ indicate that the model (3) with TIMSS95 is better.

In models (5-6) GR05-10 was used as a dependent variable and GDP95, PRIM95, SEC95, TER95 and TIMSS95 as explanatory variables. With exception of GDP10 in the model (6) none partial regression coefficient was statistically significant. Nevertheless, both models were statistically significant according to their $F$-value, and as in models (3-4) the model with TIMSS95 provided the better fit.

In models (7-8) GR00-10 was used as a dependent variable and TIMSS95 resp. TER95 variables along with GDP95 as explanatory variables. In this comparison of TIMSS95 resp. TER95 the model with TIMSS95 provided the better fit.

Finally, in models (9-10) school-enrollment rates from 1990 (model 9) and 2000 (model 10) were used as independent variables for the comparison with the model (4), where school-enrollment rates from 1995 were utilized. From explanatory variables of all three models only SEC90 was found statistically significant. The goodness-of-fit of models (9-10) was found to be better than of the model (4). This result indicates that for the explanation of the economic growth of 21 selected countries during 2000-2010 
school-enrollment rates from 1990 and 2000 has more predictive power than schoolenrollment rates from 1995.

Among all explanatory variables of the economic growth of selected countries during 2000-2010 used in this study, GDP per capita in 1995 was the most important (the most statistically significant) variable. Partial regression coefficients of school-enrollment rates and TIMSS95 were found to be statistically insignificant in most of the models, but majority of models was statistically significant as a whole. Moreover, all models with TIMSS95 among explanatory variables provided better fit of the data than their counterparts without TIMSS95.

Also, possible multicollinearity in the regression models was examined. Multicollinearity does not affect reliability of a regression model as a whole, but it affects individual predictors, see Kennedy (2003). For the detection of multicollinearity some approaches were proposed, but there is no test of statistical significance for multicollinearity yet (Kennedy 2003). In models (1-10) mostly PRIM95, SEC95, TER95, GDP95 and TIMSS95 were used as independent variables. At first pairwise correlation coefficients among these variables were examined. Multicollinearity can be expected when a correlation coefficient exceeds value of 0.8 . From Table 4 can be seen that pairwise correlation coefficients of the variables are smaller than 0.8 , as they range from 0.275 to 0.732 . Another commonly used measure of multicollinearity is variance inflation factor $(V I F)$, see O'Brian (2007): $\operatorname{VIF}(i)=\frac{1}{1-R_{i}^{2}}$, where $R_{i}^{2}$ is the coefficient of determination of a regression of a variable $(i)$ on other variables in the model. Values $V I F(i)>10$ indicate multicollinearity. It was found that VIF values for PRIM95, SEC95, TER95, GDP95 and TIMSS95 were: 3.34, 11.6, 1.70, 1.22 and 5.58. These results indicate that there might be problem with SEC95. However, as stated in O'Brian (2007): 'Values of the VIF of 10, 20, 40 or even higher do not, by themselves, discount the results of regression analyses...'. Also, O'Brian (2007) doesn't recommend dropping one of variables, as in this case a model changes into a new model, which is not theoretically well motivated and this new regression might cause even more severe problems than the original regression. Instead, he suggests to use Ridge Regression. Generally, multicollinearity can be reduced by obtaining more (uncorrelated) data, but in the case of this research it was not possible (there are no other TIMSS 95 data). 
Table 4

The Correlation Matrix of All Variables

\begin{tabular}{|l|r|r|r|r|r|r|r|r|r|r|r|r|l|l|}
\hline & TIMSS95 & PRIM90 & PRIM95 & PRIM00 & SEC90 & SEC95 & SEC00 & TER90 & TER95 & TER00 & GDP95 & GDP10 & GR05-10 & GR00-10 \\
\hline TIMSS95 & 1.000 & & & & & & & & & & & & & \\
\hline PRIM90 & 0.043 & 1.000 & & & & & & & & & & & & \\
\hline PRIM95 & -0.536 & 0.573 & 1.000 & & & & & & & & & & & \\
\hline PRIM00 & 0.012 & 0.094 & 0.456 & 1.000 & & & & & & & & & & \\
\hline SEC90 & 0.766 & 0.159 & -0.229 & 0.183 & 1.000 & & & & & & & & & \\
\hline SEC95 & 0.732 & 0.524 & 0.520 & 0.332 & 0.631 & 1.000 & & & & & & & & \\
\hline SEC00 & 0.602 & 0.333 & -0.035 & 0.186 & 0.512 & 0.880 & 1.000 & & & & & & & \\
\hline TER90 & 0.284 & 0.480 & -0.031 & -0.126 & 0.404 & 0.129 & 0.137 & 1.000 & & & & & & \\
\hline TER95 & 0.350 & 0.700 & 0.275 & -0.146 & 0.371 & 0.431 & 0.366 & 0.890 & 1.000 & & & & & \\
\hline TER00 & 0.534 & 0.685 & 0.208 & 0.066 & 0.392 & 0.491 & 0.582 & 0.605 & 0.749 & 1.000 & & & & \\
\hline GDP95 & 0.614 & -0.047 & -0.483 & -0.084 & 0.437 & 0.325 & 0.285 & 0.393 & 0.495 & 0.506 & 1.000 & & & \\
\hline GDP10 & 0.696 & 0.118 & -0.393 & -0.130 & 0.445 & 0.495 & 0.379 & 0.421 & 0.559 & 0.519 & 0.972 & 1.000 & & \\
\hline GR05-10 & -0.334 & 0.035 & 0.383 & 0.391 & -0.086 & 0.003 & -0.105 & -0.072 & -0.231 & -0.206 & -0.527 & -0.466 & 1.000 & \\
\hline GR00-10 & -0.366 & -0.127 & 0.191 & 0.210 & -0.108 & -0.309 & -0.160 & -0.099 & -0.348 & -0.201 & -0.764 & -0.682 & 0.792 & 1.000 \\
\hline
\end{tabular}

Table 5

\section{Multiple Linear Regression Models}

\begin{tabular}{|c|c|c|c|c|c|c|c|c|c|c|}
\hline Models & (1) & (2) & (3) & (4) & (5) & (6) & (7) & (8) & (9) & (10) \\
\hline $\begin{array}{l}\text { dependent } \\
\text { variable }\end{array}$ & GDP10 & GDP10 & GROO-10 & GR00-10 & GR05-10 & GR05-10 & GR00-10 & GR00-10 & GR00-10 & GR00-10 \\
\hline$n$ & 19 & 19 & 18 & 18 & 18 & 18 & 20 & 19 & 18 & 17 \\
\hline$R^{2}$ (adj.) & 0.832 & 0.660 & 0.706 & 0.487 & 0.863 & 0.482 & 0.530 & 0.178 & 0.669 & 0.686 \\
\hline $\begin{array}{l}\text { F significance } \\
\text { ( } p \text {-value) }\end{array}$ & $4.51 \mathrm{e}-06$ & 0.00022 & 0.00087 & 0.0113 & 0.000011 & 0.0119 & 0.00064 & 0.0810 & 0.00078 & 0.00096 \\
\hline const. & $-127.484^{*}$ & 49.959 & -7.237 & 4.853 & -2.135 & 0.764 & $3.589^{* * *}$ & $5.342^{\star \star \star}$ & $6.789^{\star \star \star}$ & 5.35321 \\
\hline GDP95 & - & - & -0.04979 & $-0.0973^{\star *}$ & -0.0245 & $-0.0658^{*}$ & $-0.1389^{\star \star \star}$ & $-0.1120^{\star \star}$ & $-0.1529^{* * *}$ & $-0.1142^{\star \star *}$ \\
\hline TIMSS95 & $0.2308^{\star \star *}$ & - & 0.0043 & - & -0.0073 & - & 0.0050 & - & - & - \\
\hline PRIM90 & - & - & - & - & - & - & - & - & -0.0241 & - \\
\hline PRIM95 & 0.6053 & -0.5139 & 0.1289 & 0.0075 & 0.0606 & 0.0218 & - & - & - & - \\
\hline PRIMOO & - & - & - & - & - & - & - & - & - & 0.00017 \\
\hline SEC9O & - & - & - & - & - & - & - & - & $0.0190^{*}$ & - \\
\hline SEC95 & -0.2574 & $0.2315^{\star \star}$ & -0.0252 & -0.00033 & 0.0260 & 0.0131 & - & - & - & - \\
\hline SECOO & - & - & - & - & - & - & - & - & - & -0.0038 \\
\hline TER90 & - & - & - & - & - & - & - & - & 0.0049 & - \\
\hline TER95 & $0.2125^{\star \star}$ & $0.2708^{\star \star \star}$ & $-0.0146^{*}$ & -0.0041 & -0.0046 & -0.0067 & - & 0.0039 & - & - \\
\hline TEROO & - & - & - & - & - & - & - & - & - & 0.0176 \\
\hline
\end{tabular}

The legend: "partial regression coefficient significant at $\alpha=0.10$ level, ${ }^{* *}$ at $\alpha=0.05$ level, ${ }^{* * *}$ at $\alpha=0.01$ level. 


\section{Conclusions}

In this study TIMSS scores of 21 countries from 1995 were examined in a relation to the economic growth after 10-15 years. Traditionally, human capital of nations is expressed by literacy rates or school-enrollment rates. However, these variables cannot capture quality of education, but TIMSS scores can, so they can aspire on proxies of human capital as well.

In the empirical part of this paper it was found that TIMSS scores from 1995 strongly positively correlate with GDP per capita in $2010(r=0.696$, statistically significant at $\alpha=0.01$ ). This correlation is higher than correlations between school-enrollment rates from 1995 and GDP per capita in 2010, which were found statistically insignificant at $\alpha=0.01$ level.

To compare TIMSS with school-enrollment rates as proxies for human capital 12 simple and 10 multiple linear regression models were examined. In simple linear models TIMSS and school-enrollment rates were explanatory variables for GDP per capita in 2010 and mean GDP growth during 2005-2010 and 2000-2010. Results of these models suggest that TIMSS is a suitable proxy of human capital, as it was highly statistically significant (at $\alpha=0.01$ ) in two out of three models. The positive values of regression coefficients in these models reflect expectations that higher TIMSS scores lead to the higher GDP growth after one and a half decade. Open question remains why TIMSS was statistically significant in the model with mean GDP growth during 2005-2010 as a dependent variable, but not for the longer 2000-2010 period.

Primary and secondary school-enrollment rates were statistically significant only in one model out of three, while tertiary school-enrollment rates were significant in all three models, but in two models the regression coefficient was negative - a result which is somewhat counterintuitive.

From multiple linear regression models with the same dependent variables it was learned that integration of TIMSS scores into models leads to their substantial improvement, although partial regression coefficients for TIMSS were statistically significant only in the case of GDP per capita in 2010. However, the same applies to school-enrollment rates, which were also statistically insignificant in most cases. The most important (the most statistically significant) explanatory variable of the economic growth was GDP per capita in 1995. This (collateral) result of this study is in agreement with the neoclassical model of economic growth, which states that poorer countries tend to grow faster than rich ones.

Thus, the answer to the question in the paper's heading is yes: TIMSS scores can be considered suitable proxies of human capital.

However, this answer must be treated with some caution due to limitations of the presented study, namely its database, for data quality is crucial in empirical analysis (see Cohen and Soto 2007). Firstly, the data included only 21 countries, mainly developed countries 
from Europe; Americas were represented by only two countries, as well as Oceania, and from Africa only data from the South Africa were at the disposal. Also, some data for school-enrollment rates were missing, and TIMSS scores for some countries (though the sample was quite large) were obtained by improper sampling. Secondly, the lag of 5-15 years between TIMSS and period for which GDP was taken might be too short. Since TIMSS 1995 other international studies of students' achievements took place, such as PISAs (Programme for International Student Assessment, in 2000, 2003, 2006 and 2009) or later TIMSSs (in 1999, 2003 and 2007). It would be interesting to combine results from TIMSS and PISA in the same way as primary, secondary and tertiary schoolenrollment rates are used to express human capital, and to compare these results with economic growth after several years or a decade.

\section{References:}

Barro, R. (1991), "Economic Growth in a Cross Section of Countries." Quarterly Journal of Economics, Vol. 106, No. 2, pp. 407-443.

Barro, R., Salla-i-Martin, X. (1995), Economic Growth. New York: McGraw-Hill

Becker, G. S. (1993), Human Capital: A Theoretical and Empirical Analysis, with Special Reference to Education, $3^{\text {rd }}$ ed. Chicago: University of Chicago Press.

Becker, G. S., Murphy, K. M., Tamura, R. (1990), "Human Capital, Fertility, and Economic Growth." Journal of Political Economy, Vol. 98, No. 5, pp. 12-37.

Castelló-Climent, A. (2010), "Channels through which Human Capital Inequality Influences Economic Growth." Journal of Human Capital, Vol. 4, No. 4, pp. 394-450.

Cohen, D., Soto, M. (2007), "Growth and Human Capital: Good Data, Good Results." Journal of Economic Growth, Vol.12, No. 1, pp. 51-76.

Jones, C. I. (1996), "Human Capital, Ideas and Economic Growth.” Mimeo, Stanford University.

International Monetary Fund (2011), World Economic Outlook Database. http://www.imf. org/external/ pubs/ft/weo/2011/01/weodata/index.aspx. Accessed on 10 April 2011.

Kennedy, P. (2003), A Guide to Econometrics, $5^{\text {th }}$ edition. Cambridge: MIT Press.

Lucas, R. E. (1988), On the Mechanics of Economic Development. Journal of Monetary Economics, Vol. 22, pp. 3-42.

Mazouch, P., Fischer, J. (2011), Lidský kapitál - měření, souvislosti, prognózy. Praha: C. H. Beck, 2011.

Nelson, R. R., Phelps, E. S. (1966), "Investment in Humans, Technological Diffusion and Economical Growth." American Economic Review Proceedings, Vol. 56, pp. 69-75

O'Brian, R. M. (2007), "A Caution Regarding Rules of Thumb for Variance Inflation Factor." Quality and Quantity, Vol. 41, No. 5, pp. 673-690.

Romer, P. M. (1990), “Endogenous Technological Change.” Journal of Political Economy, Vol. 98, No. 5, pp. 71-102.

Solow, R. M. (1956), "A Contribution to the Theory of Economic Growth." Quarterly Journal of Economics, Vol. 70, pp. 65-94.

UNESCO (1998), Human Development Indicators - Report. Available at http://hdr.undp.org/en/media / hdr_1998_en_contents.pdf. Accessed 10 November 2011.

TIMSS home page. (1995), Available at http://timss.bc.edu/timss1995.html. Accessed on 15 November 2011. 
TIMSS test items. (1995), Available at http://timss.bc.edu/timss1995i/TIMSSPDF/C_items.pdf. Accessed 15 November 2011.

Temple, J. (1999), “A Positive Effect of Human Capital on Growth.” Econ. Letters, Vol. 65, pp. 131-134.

Wilson, R. A., Briscoe, E. (2004). The Impact of Human Capital on Economic Growth: A Review. In: Impact of Education and Training, the Third Report on Vocational Research in Europe: Background Report, Luxembourg: Office for Official Publications of the European Communities.

World Bank. (2010). Available at http://data.worldbank.org/topic/education. Accessed on 15 November 2011. 